\title{
后疫情时期基于 SPOC 的商务英语写作课程混合式教学设计
}

Mixed Teaching Design of Business English Writing Course Based on SPOC in Post-Epidemic

Period

刘俊

Jun Liu

武汉文理学院 中国·湖北 武汉 432200

Wuhan College of Arts and Science, Wuhan, Hubei, 432200, China

摘 要: 新冠疫情期间的线上教学推动了教育信息化的深化，如何在后疫情时期进一步融合在线教育与线下课堂的问题摆 在一线教师面前。本研究以 SPOC $+\mathrm{f} 2 \mathrm{f}$ 教学为出发点, 以商务英语写作课程为例, 探析基于 SPOC 的混合式教学模式, 以 期充分利用优质网络教育资源，进一步提高教学质量。

\begin{abstract}
Online teaching during the COVID-19 epidemic has facilitated the education informatization. The question of how to further integrate online teaching and face-to-face teaching in the post-COVID-19 era arises. This study, from the view of SPOC $+\mathrm{f} 2 \mathrm{f}$ teaching, takes business English writing course as an example to explore the blended teaching mode based on SPOC, aimed to make full use of quality resources and improve the teaching quality.
\end{abstract}

关键词: SPOC; 混合式教学; 商务英语写作棵程

Keywords : SPOC; blended teaching mode; business English writing course

DOI: $10.36012 /$ sde.v2i11.2386

\section{1 引言}

疫情期间停课不停学给高校教育带来了挑战, 也带来了 进一步深化教育信息化的机遇。随着互联网信息技术、电子 产品技术的发展，互联网 + 教育成为后疫情时期的发展趋势， 在线教育将进一步融入传统课堂教学。慕课、微课、翻转课 堂等教学模式已成为高校教学改革的主要形式, 如何进一步 融合线下课堂与在线教育进行混合教学再次成为后疫情时 期教育工作者研究的热点。

\section{2 混合式教学的定义及特点}

混合式教学起源于远程教育，包含教与学两个方面。 一般认为混合学习是面对面 (Face-to-face) 学习和技术辅助 学习的结合。Berta 和 Stacey 将混合学习细分为两种形式： Hybrid Teaching 和 Blended Teaching : 前者将课程时间按照
灵活的比例分配给实体课堂和线上教学，而后者视在线学习 为传统面对面课堂学习的补充，不占用课堂时间。混合式教 学广泛利用教学资源, 采用多种教学策略, 强调教师、学生 和资源间的互动, 以学生为中心 , 是多维互动、动态开放和 以生为本的新型教学模式。各国学者大多认同混合教学相比 传统教学模式更有利于学习, 通过混合模式, 学生能够获得 丰富资源, 更深入地探索学习主题, 更自由地互动; 注重学 生的需求，提高灵活性、满意度和批判性思维技能。但是学 习者对混合式学习的满意度取决于教学、互动、教师、技术 和课程管理等因素。

\section{3 基于 SPOC 的商务英语写作混合式教学}

\subsection{SPOC 课程的特点及优势}

作为一种在线教学模式, SPOC (Small Private Online

【作者简介】刘俊 $(1981 \sim)$, 女, 湖北钟祥人, 讲师，从事商务英语教学、跨文化研究。 
Course）避开了 MOOC 因其规模大、人数多、无时限而导 致的教学质量管理困境，具有独特的优势。SPOC 由教师根 据教学大纲和 $\mathrm{f} 2 \mathrm{f}$ 教室教学内容, 选择优质资源, 制定在线 学习内容, 发布学习任务, 检查学生在线学习情况, 及时反 馈检查结果, 并因此灵活地调整 $\mathrm{f} 2 \mathrm{f}$ 实体课堂教学内容, 完 成网络课堂答疑 ; 学生根据老师的任务清单在规定时间内完 成课前预习和课后作业。SPOC 成为实体课堂教学之外灵活 而有效的补充, 和传统教学模式有效地衔接、融合成混合教 学模式。

\section{2 商务英语写作 SPOC 课程的背景}

武汉文理学院商务英语专业的商务英语写作课程于第 6 学期开设, 但学生大三才开始学习商务类专业课程, 商务 类知识积累不够。在这种情况下, 32 课时内学习商务写作 知识与技能有些捉襟见肘。疫情期间, 根据人才培养目标及 教学大纲，该课程采用了中国大学慕课平台的国家精品课程 “外经贸英语函电”。考虑到课时限制和学生学情, 该 SPOC 课程主要用于课前预习、课后检测、作业及评价, 教师结合 $Q Q$ 直播、 $Q Q$ 课堂等在线面对面教学方式, 顺利完成了既 定教学任务, 学生在课程结束时以良好的成绩通过了考试。 当疫情得到控制, 教学回归正常, 并不意味师生放弃优质的 教学资源, 相反, 混合式教学模式在互联网 + 的时代应大 有作为。

\section{3 商务英语写作课程混合式教学设计}

在混合式教学中, 教师不只是讲师和课堂管理者, 更 是信息管理者和促进者, 是课程资源学习者、整合者和线上 学习指导者。教师在课前根据学生的需求整合各种在线和实 体课程资源, 组织、指导并促进学生的课堂学习 ${ }^{[1]}$ 。这对教 师在课程教学设计方面提出了更高的要求。基于 SPOC 课程, 本研究以商务英语写作课为例, 设计课前、课中和课后三个 阶段的混合式教学模式。

(1)课前预学。该 SPOC 课程共 12 章, 每章包含背景知 识导入及写作要点讲解视频、知识问答、单元测试和拓展资 源。该阶段主要包括定期发布视频教学材料，布置课前讨论、 课程前测等任务。当学生登录慕课平台进入 SPOC 课程, 后 台将自动记录学生的学习行为, 展示学习频次、时长及成绩 等。教师可通过成绩管理和课程数据了解学习进度及测验成 绩, 掌握学生的薄弱点, 在 f $2 \mathrm{f}$ 课堂教学中有针对性地补充
重难点讲解。

(2)课堂教学。课前 SPOC 预习专业背景知识为师生省 出课堂活动时间，支持教师将时间和精力转向更高价值的活 动, 如案例分析、商务语言学习、小组讨论等。基于学生线 上预习外贸专业知识的成果，该阶段以传统面对面教学为 主, 教师在课堂重点讲解写作技巧, 赏析范例, 分组讨论; 通过与学生分享真实的语言素材和商务案例, 带领学生批判 性反思商务语言沟通的原则和技巧等，使师生、生生、学生 与资源间的交互更高效; 允许学生批判性地反思学习内容和 经历, 深入理解商务语言和文化差异, 有助于培养学生的商 务沟通能力和跨文化能力。

(3)课后巩固。课后巩固以写作练习和单元测试为主。教 师通过 SPOC 布置写作任务, 并设置学生自评、互评和教师 点评功能, 完成作业提交、自评和作品互评的学生将获得相 应成绩。学生之间互评不仅包括给分数, 还须写下评语, 这 也加深了学生与同伴、与材料之间的有效交互，提高了学生 参与写作评价与反馈的积极性，从而提高其写作学习的效果。

单元测试检查学生掌握商务知识、写作技巧和常用句 式等知识与技能的情况 ${ }^{[2]}$ 。学生完成测试后通过查看答案解 析掌握知识点, 教师通过成绩管理掌握班级和个体的情况, 并在下一次的课堂教学中进行反馈。

混合式教学模式也为教师建立过程性评价和结果性评 价相结合的评价体系。SPOC 帮助教师采集分析学习行为数 据，掌握学生的学习动态，使过程性评价更具操作性，方便 教师及时准确地干预低效的学习行为。

\section{4 结语}

基于 SPOC 的混合式教学要求老师依托信息技术，采 用不同教学方法和策略, 多角度调动学生预习的积极性, 鼓 励学生自主学习, 进行移动学习、碎片化学习, 实现对学生 的多维度测评和有效交互，促进更深层次学习和批判性反 思, 才能提高教学效果。

\section{参考文献}

[1] 李逢庆. 混合式教学的理论基础与教学设计 [J]. 现代教育技术, 2016, 26(9):18-24.

[2] 刘洋. 混合式教学的困境与优化 [J]. 教学与管理, 2020(18):104106. 